\title{
Inefficiency of manual weeding in rainfed rice systems affected by parasitic weeds
}

Simon Akahoua N'cho, Monique Mourits Jonne Rodenburg Alfons Oude Lansink

\begin{abstract}
Manual weeding is the predominant weed control practice and the most laborconsuming activity in smallholder, rainfed rice systems in sub-Saharan Africa. This study investigates the technical inefficiency of weeding labor, other labor, and overall inputs, and identifies sources of technical inefficiency of weeding labor in the context of parasitic weed infestation. The analysis applies a two-stage approach. First, a directional input distance function DEA approach was used to compute input-specific technical inefficiencies. Second, sources of technical inefficiency of weeding labor were identified using a truncated bootstrap regression. Data from 406 randomly selected smallholder farmers from Benin $(n=$ $215)$ and Côte d'Ivoire $(n=191)$ were used. The technical inefficiency of weeding labor was high in both countries (58\% in Côte d'Ivoire and 69\% in Benin). This implies that a substantial fraction of weeding labor could be saved without reducing rice productivity or increasing the use of other inputs. A decrease in the technical inefficiency of weeding labor with an increase in production scale was observed. In addition, weeding regime and education level were each associated to significant changes in the technical inefficiency of weeding labor.
\end{abstract}

\section{Introduction}

In sub-Saharan Africa (SSA), cereal crop production, in particular rainfed rice, is negatively affected by weeds (Becker and Johnson, 2001; Oerke, 2006; Oerke and Dehne, 2004;

Waddington et al., 2010). Among biotic constraints, weeds are consistently cited to cause the highest crop damage (Demont et al., 2009; Oerke, 2006). Damage due to weeds results in both direct and indirect yield losses (Chambers et al., 2010), as weeds are known to attract other biotic yield-reducing factors such as viral diseases and grain-feeding birds (Demont and Rodenburg, 2016; Heinrichs et al., 1997). Smallholders with weed-infested fields also have higher on-farm workloads, reduced time for other productive activities, and higher production costs (Adesina et al., 1994; Demont et al., 2007). The predominant weed control practice in smallholder rainfed rice systems consists of manual weeding (Adesina et al., 1994; N'cho et al., 2014; Tippe et al., 2017a), while herbicides are only used by one-third of the smallholder farmers in SSA (Rodenburg et al., 2019). This explains why for the majority of farmers in these systems, weeding take up more than $50 \%$ of the available farm labor (Akobundu, 1981; Stessens, 2002). Manual weeding is time consuming (Ogwuike et al., 2014) and the amount and costs of weeding labor is a primary concern

(Ruthenberg, 1980). More efficient weeding strategies could save farmers' time and money to be allocated to other activities. In addition, the damage caused by weeds is another important concern. Weed-inflicted damage is particularly problematic in case of parasitic weed species. 
Parasitic weeds form a special weed group. In addition to the ordinary crop-weed competition for resources, they parasitize their host (the crop) to extract resources (water, nutrients, and metabolites). By changing the host plant's hormone balance, they negatively affect the crop (Parker and Riches, 1993). Parasitic weeds cause important yield losses across crops and regions throughout the world (N'cho et al., 2017; Parker, 2012). In rainfed rice systems in SSA, the parasitic weed species Rhamphicarpa fistulosa (Rice vampire weed), Striga asiatica, Striga aspera, and Striga hermonthica (Witchweed) cause increasing problems (Rodenburg et al., 2010, 2015). These weeds affect rice production in at least 30 countries in SSA, causing crop losses that amount up to U.S. \$200 million each year, even using conservative estimates (Rodenburg et al., 2016). As hand weeding is the most used management option in rainfed rice systems (Ogwuike et al., 2014), rethinking the role of weeding labor is crucial to improve productivity of these systems. Labor, and in particular weeding labor, is the most constraining input factor in smallholder rainfed rice production systems in SSA. However, the current understanding of the manual weeding efficiency or the effects of weeds or parasitic weeds on input use efficiencies is limited.

Manual weeding is tedious, highly labor-intensive, time consuming, and often not completed in time (Gongotchame et al., 2014; Rodenburg and Johnson, 2009). The delay results in high yield losses, as weeds will unduly compete with the crop for resources, and therefore in increased technical inefficiency (Akobundu, 1981). Because of the additional yield-reducing effects of parasitism, weed infestations might cause an even higher technical inefficiency. Hence, it is worthwhile to investigate the efficacy of weeding labor in smallholder, rainfed rice production systems and to explore how parasitic weed infestation affects the overall efficiency of weeding labor.

This study aims to investigate (1) the technical inefficiency of weeding labor, other labor, and overall inputs, and (2) the main determinants of technical inefficiency of weeding labor in the context of rainfed rice production in the presence of parasitic weeds. Published empirical studies that deal with the efficiency of manual weeding or with the effects of parasitic weeds on the efficiency of input use are scant. This article uses a directional distance function and Data Envelopment Analysis (DEA) to measure technical inefficiency of weeding labor, other labor, and overall inputs, and it identifies the main determinants of technical inefficiency in weeding labor using a truncated bootstrap regression model (Simar and Wilson, 2007). The analysis in this article is based on farmer-specific data collected in parasitic weed-infested rainfed rice production regions of Benin and Côte d'Ivoire during the cropping season of 2011-2012.

\section{Methods}

\subsection{Input-specific DEA model}

DEA is a nonparametric approach to measuring efficiency. The method has been widely applied in a variety of industries including agriculture (Simar and Wilson, 2007). In this study, the input-specific efficiency is estimated using a directional input distance function DEA to compute subvector inefficiency scores pertaining to a particular input. This allows an estimation of the extent to which the target input can be saved, keeping the observed output constant and using the same quantity of other inputs (Färe et al., 1994; Oude Lansink et al., 2002; Oude Lansink and Silva, 2004). Using this specification, the inefficiencies of the target inputs (i.e., weeding labor, other labor, or overall inputs) were computed directly. The 
subvector technical inefficiencies were measured using the directional input distance function as defined by Chambers et al. (1996). Assuming that the production technology of rainfed rice systems is appropriately represented by the directional input distance function, and that farmers produce a vector of outputs $y$ from a vector of inputs $x$, decomposed in the target input $\left(x_{i}\right)$ and nontarget inputs $\left(x_{k-i}\right)$, the input requirement set of the farming system technology is given by:

$L(y)=\{(x, y)$ such that $x$ can produce $y\}$

Following Chambers et al. (1996) and assuming convexity and free disposability of inputs for the farming system technology, the directional input distance function is defined as $\vec{D}_{I}: \Re_{+}^{M} \times \Re_{+}^{N} \times \Re^{N} \rightarrow \Re$,

$$
\begin{aligned}
\vec{D}_{I}\left(x_{i}, x_{k-l}, y ; g_{x_{i}}\right) & =\sup _{\beta}\left\{\beta \in \Re: x_{i}-\beta g_{x_{i}} \in L(y)\right\} \\
& =\sup \left\{\beta \in \Re: x_{i} \in \beta g_{x_{i}}+L(y)\right\},(2)
\end{aligned}
$$

where $y \in \Re_{+}^{M}$ is a vector of outputs, $x_{i} \in \Re_{+}^{N}$ is a vector of target input, $x_{k-i} \in \Re_{+}^{N}$ is a vector of nontarget inputs, the technology is represented by the input

correspondences $L: \Re_{+}^{M} \rightarrow \Re_{+}^{N}$ which define input sets $L(y) \subset \Re_{+}^{N}$ (Fig. 1 ), and $g_{x_{\mathrm{i}}}$ is a nonzero vector in $\Re_{+}^{N}$ defining the direction in which $\vec{D}_{I}(\cdot)$ is defined. In the short run, the directional input distance function gives an estimation of the maximum contraction in the specific input(s) (second line of Eq. 2) or the maximal translation of $L(y)$ (third line of Eq. 2 ) along $g_{x_{\mathrm{i}}}$ that permits keeping the input $(x)$ feasible (to reach the frontier) while keeping output $(y)$ and nontarget inputs $\left(x_{k-i}\right)$ constant (Fig. 1).

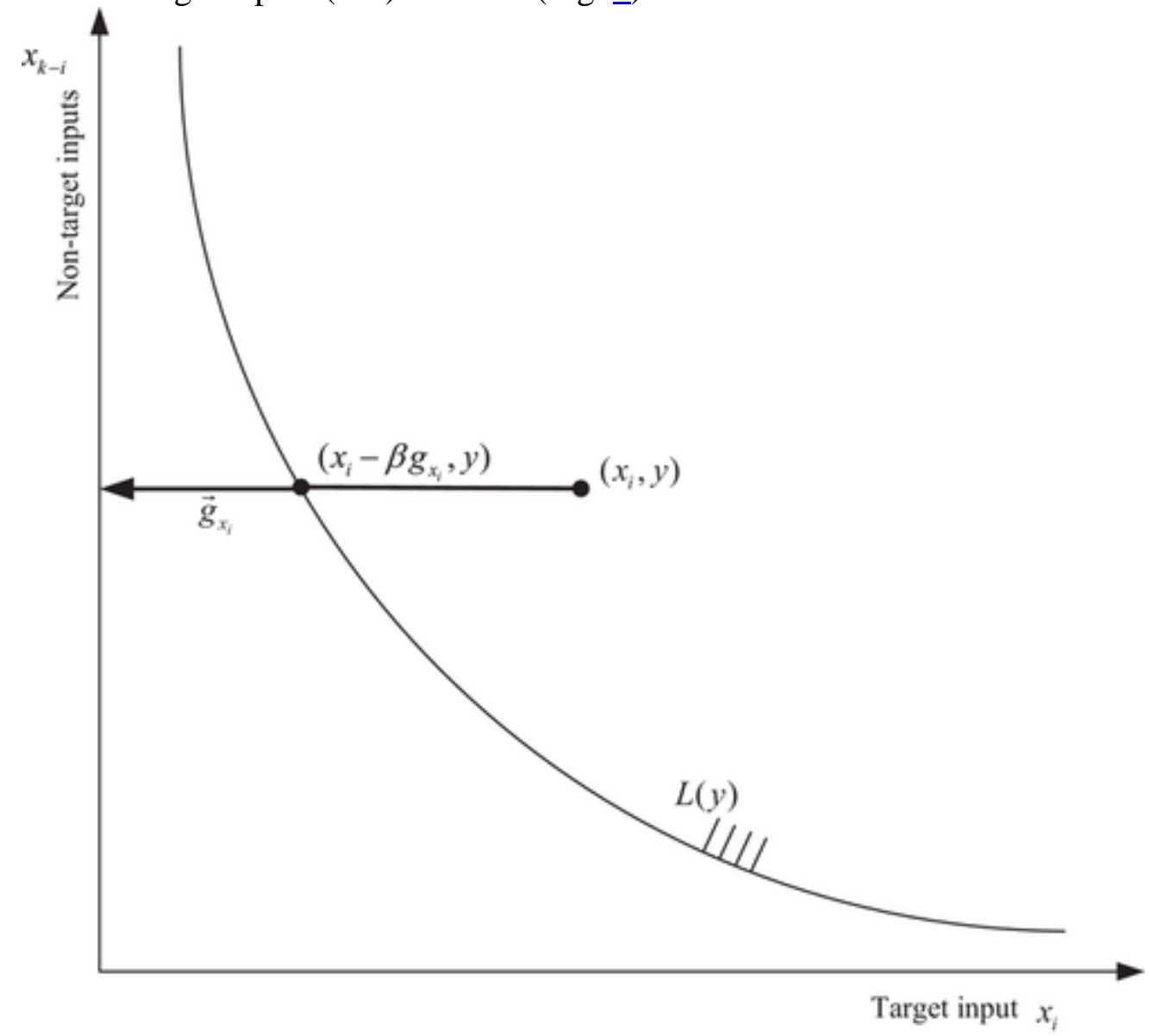

Figure 1 
Open in figure viewerPowerPoint

Directional input distance function.

In this study, the optimal input set varies for each farmer. Therefore, the realized input-output vector $\left(x_{i}, y\right)$ was used for the input-specific technical inefficiency measurement (Chambers et al., 1998; Singbo and Oude Lansink, 2010). For the technical inefficiency relative to variable returns to scale (VRS), the function used in the directional distance function technology is described across the $k(k=1, \ldots, K)$ inputs and outputs as:

$\vec{D}_{I}\left(x_{i}, x_{k-i}, y ; g_{x_{i}} \mid V R S\right)=\min _{\beta, \lambda} \beta^{i}$

S.t.

(1) $\mathbf{Y} \lambda \geq y$,

(2) $\mathbf{X}_{i} \lambda \leq x_{i}-\beta^{i} x_{i}$,

(3) $\mathbf{X}_{k-i} \lambda \leq x_{k-i}$,

(4) $\mathbf{I}^{\prime} \lambda=1$,

(5) $\lambda \geq 0$,

where, $\mathbf{Y}$ is the $(N \times 1)$ vector of observed outputs, $y$ is the observed output level, $\boldsymbol{X}_{\boldsymbol{i}}$ and $\mathbf{X}_{\boldsymbol{k}-\boldsymbol{i}}$ are the $(N \times K)$ matrix of target and nontarget inputs, $\beta$ is a scalar, $\mathbf{I}$ is the $(N \times 1)$ unitary vector, and $\lambda$ is an $(N \times 1)$ vector of constants (firms weights). Constraints 2 and 3 ensure that the solution of the model finds a value of $\beta^{i}$ representing the maximum reduction in the target input $i$ within the technology set holding all nontarget inputs and the output constant. Constraint $4,\left(I^{\prime} \lambda=1\right)$, is the convexity constraint which imposes VRS to the model. Using the unknown parameters $\lambda$ and $\beta$, the model is solved once for each farmer. The estimates lie between zero and one. An estimated value of zero for $\beta$ represents a fully efficient farmer, located on the efficient frontier (Fig. 1). For such a farmer, there is no possibility to reduce the target input use without reducing rice production level or increasing the nontarget inputs. An estimated value greater than zero indicates the existence of technical inefficiencies. This implies that a share of the target input can be saved. The VRS specification allows farming systems to exhibit increasing, constant, or decreasing returns to scale (DRS). However, Coelli et al. (2002) and Haji (2007) found that economies of scale were absent in smallholder farming systems such as the one considered in this study. Hence, a constant returns to scale (CRS) specification may suffice. For this reason, both the VRS and CRS specifications were considered, allowing the computation of scale inefficiency. ${ }^{1}$ The CRS specification $\underset{I}{\vec{D}}\left(x_{i}, x_{k-i}, y ; g_{x_{i}} \mid C R S\right)$ was computed as in Eq. $\underline{3}$ by removing the convexity constraint, $\boldsymbol{I}^{\prime} \boldsymbol{\lambda}=1$ from the model. This specification assumed that farms operate at their optimal scale (Speelman et al., 2008).

The convexity restriction $\boldsymbol{I}^{\prime} \lambda \leqslant 1$ in $\vec{D}_{i}\left(x_{s}^{k^{\prime}}, y^{k^{\prime}} ;-x_{s} \mid N I, R S\right)$ and $\boldsymbol{I}^{\prime} \lambda \geq 1$ in $\vec{D}_{i}\left(x_{s}^{k^{\prime}}, y^{k^{k}} ;-x_{s} \mid N D, R S\right)$ displays Non-Increasing (NI-RS) and Non-Decreasing (ND-RS)

Returns to Scale, respectively. Hence, to determine the nature of the returns to scale, ${ }^{-}$we used the directional technology scale efficiency definition 2 as proposed by Fukuyama (2003). The DMU (Decision Making Unit) exhibits a:

1. DRS for $(x ; y)$ if

$$
\vec{D}_{i}^{V}(x, y)=\vec{D}_{i}^{N I}(x, y)<\vec{D}_{i}^{C}(x, y),
$$

2. Increasing returns to scale (IRS) for $(x ; y)$ if 


$$
\vec{D}_{i}^{V}(x, y)<\vec{D}_{i}^{N I}(x, y)=\vec{D}_{i}^{C}(x, y),
$$

3. CRS for $(x ; y)$ if

$$
\vec{D}_{i}^{V}(x, y)=\vec{D}_{i}^{N I}(x, y)=\vec{D}_{i}^{C}(x, y), .
$$

where $\vec{D}_{i}^{N I}(x, y)$ is the Farrell input-oriented NI-primal formulation, and $\vec{D}_{i}^{V}(x, y)$ and $\vec{D}_{i}^{C}(x, y)$ are VRS and CRS formulations, respectively.

The overall input technical inefficiency and subvector inefficiencies were estimated ${ }^{3}$ in R3.0.1 using the routine dea.direct of FEAR.2.0 (Frontier Efficiency Analysis with R) package (Wilson, 2008). The overall input inefficiency (INIE) was estimated as in Eq. $\underline{3}$ by pulling together all variable inputs including weeding labor, in constraint 2 , while only fixed inputs remained unchanged in constraint 3 . Since the two countries operate in different environments and crop management settings, we estimated separate frontiers. Moreover, results from the Meta frontier (single frontier for both countries together) estimation were not consistent with the sample data.

\subsection{Comparing technical efficiency of parasitic weed-infested farms to noninfested farms}

To show the correlation between the distributions of inefficiency scores on infested and noninfested farms, equality of distribution was tested for the overall technical inefficiency and weeding labor technical inefficiency for the subsamples of parasitic weed-infested farms and noninfested farms. Since the technical inefficiency scores are unobserved, the statistics provided by the nonparametric independence tests (Person's chi-square, likelihood ratio, and Kendall tau rank correlation tests) are not valid (Simar and Zelenyuk, 2006). Hence, to test the equality of distribution of technical inefficiency scores on parasitic weed-infested farms against noninfested farms in this study, the adapted Li test by Simar and Zelenyuk (2006) was most appropriate and performed in R3.0.1.

\subsection{Truncated bootstrap model}

To examine the existing correlation between efficiency and economic agent characteristics, several studies regressed the estimated efficiencies on a set of environmental variables (Simar and Wilson, 2007). However, the input-specific inefficiency estimate for a farmer is defined relative to the frontier representing the best practice. Consequently, the estimated DEA inefficiency scores are serially correlated (Hirschberg and Lloyd, 2002; Simar and Wilson, 2007; Xue and Harker, 1999). The structures of these complex correlations are unknown (Simar and Wilson, 2007). Hence, using these inefficiency scores in a second-stage regression analysis to explain the variation in technical inefficiency among farmers would produce invalid inference because of a violation of the basic assumption of independence within sample values. Xue and Harker (1999) and Hirschberg and Lloyd (2002) attempted to address this problem by using a naive bootstrap approach (Simar and Wilson, 2007). Unfortunately, this naive bootstrap approach appeared to be inconsistent in the context of nonparametric efficiency estimations (Simar and Wilson, 1999a, 1999b). Moreover, Simar and Wilson (2007) argued that none of these studies have described a clear data generation processes (DGP) for which these two-stage estimates would be appropriate. To overcome these difficulties, Simar and Wilson (2007) proposed single and double bootstrap procedures 
with a clear DGP. Smoothed bootstrap (Simar and Wilson, 2000) allows for heterogeneity in the distribution of the inefficiency $(\delta)$. The smoothed bootstrap permits to correct the serial correlation among the estimated inefficiency scores. And, both single and double bootstrap procedures permit valid inference for the second-stage estimation (Simar and Wilson, 2007). Hence, to identify the determinants of the inefficiency, the single bootstrap suffices. Therefore, in this study, a single bootstrap truncated regression method was used to evaluate sources explaining differences between weeding labor inefficiency among farmers (Simar and Wilson, 2007; Singbo and Oude Lansink, 2010). Following Algorithm \#1 in Simar and Wilson (2007),

1. We computed subvector ${ }^{4}$ inefficiency scores pertaining to weeding labor input using the DEA procedure as described above.

2. We regressed the estimated inefficiency scores larger than zero $\left(\hat{\delta}_{i}>0\right)$ on selected environmental variables $\left(z_{i}\right)$ using a truncated normal regression with the maximum likelihood estimator. Since inefficiency scores were used, the truncation was done at the lower bound of 0 .

3. We integrated these estimates into the smoothed bootstrap procedure of Simar and Wilson (2000) to bootstrap the truncated regression model. We draw iid bootstrap sample (see Simar and Wilson, 1999a, 1999b, 2000) data from the truncated empirical normal distribution of the estimated inefficiency scores, each of the size $m<n$ observations ( $m$ is the number of observations with inefficiency scores larger than zero $\left(\hat{\delta}_{i}>0\right), m=178<215$ for Benin and $m=154<191$ for Côte d'Ivoire). We looped over the next three steps (parametric bootstrapping) $L$ times ( $L=$ $2,000)$ to obtain a set of bootstrap estimates $\mathbf{A}=\left\{\left(\hat{\beta}^{*}, \hat{\sigma}_{\varepsilon}^{*}\right)_{b}\right]_{b=1}^{L}$. The choice of $L$ determines the number of bootstrap replications used to construct the estimates' confidence intervals, which requires more information (Simar and Wilson, 2007). Hall (1986) suggests 1,000 replications, Balezentis et al. (2014), Simar and Wilson (2007), and Yu (2003) used 2,000 replications. A larger number of replications can be used to achieve more accurate estimates at the cost of waiting time depending on the CPU power of the computer (Simar and Wilson, 2007; Yu, 2003).

- In step 3.1, for each $i=1, \ldots, m$, we draw $\varepsilon_{i}$ (the residual) from the $N\left(0, \hat{\sigma}_{E}^{2}\right)$ distribution with left-truncation at $\left(0-z_{i} \hat{\beta}\right)$.

- In step 3.2, for each $i=1, \ldots, m$, we computed $\delta_{i}^{*}=z_{i} \hat{\beta}+\varepsilon_{i}$.

- In step 3.3, we used the maximum likelihood method to estimate the truncated regression of $\delta_{i}^{*}$ on $z_{i}$, yielding estimates parameters $\left(\hat{\beta}^{*}, \hat{\sigma}_{\varepsilon}^{*}\right)$ and marginal effects of explanatory variables.

- 4 .

We used the bootstrap values in $\mathbf{A}$ and the original estimates, $\hat{\beta}, \hat{\sigma}_{\bar{E}}$ to construct a bootstrap-based confidence interval at $95 \%$ for each parameter estimate. $\underline{5}$

\section{Data description}

Via a multistage sampling process, we selected rice-producing regions and districts where parasitic weeds were present. In Benin, five districts were selected in three regions, i.e., Dassa and Glazoue in the Collines region, Kandi in the Alibori region, and Boucoumbe and Tanguieta in the Atacora region. In Côte d'Ivoire, eight districts were selected in two regions 
in the North of the country, i.e., Korhogo, Sinématiali, Karakoro, and Tioro in the Poro region, and Boundiali, Ganaoni, Siempurgo, and Kolia in the Bagoue region. The three regions in Benin accounted for $80 \%$ of the national rice area and $85 \%$ of the paddy production (DPP/MAEP, 2009). In Côte d'Ivoire, parasitic weed infestation is limited to the northern regions of the country. In Benin, we considered only Rhamphicarpa and in Côte d'Ivoire we considered both Rhamphicarpa and Striga. Both parasitic weeds are found exclusively in rainfed rice systems. Rhamphicarpa is found only in rainfed lowlands and Striga in rainfed uplands (Kabiri et al., 2015). Consequently, in Côte d'Ivoire, farmers were selected among the whole (rainfed) rice growing community, whereas in Benin only farmers of inland valleys (rainfed lowland areas) were selected. In Benin, 18 (12 infested and 6 not infested) cropped lowlands within the five districts were randomly selected. In Côte d'Ivoire, 24 villages within the 8 districts (3 villages per district) were randomly selected. At the village level in Côte d'Ivoire and at the lowland level in Benin, farmers were selected randomly. The samples comprised farmers who used manual weeding at least once during the cropping campaign 2011-2012 ( $n=215$ for Benin and $n=191$ for Côte d'Ivoire). In the random sample in Côte d'Ivoire, $43 \%$ of farmers had fields infested by either the parasitic weeds Rhamphicarpa fistulosa or Striga hermonthica (mainly) and Striga aspera. In the sample for Benin, $65 \%$ of farmers had fields infested by Rhamphicarpa fistulosa. The samples comprised $75 \%$ female rice farmers, in Benin, and 15\%, in Côte d'Ivoire. Farmers were asked about their use of farming inputs, measured by quantities and costs. The following characteristics were collected based on farmers' estimations: field infestation status (infested or not infested) and infestation intensity (low, medium, high), surface area covered by parasitic weeds, the location of the field along the upland-lowland continuum, the weeding methods, and corresponding number of weeding operations.

\subsection{Input-specific DEA model data}

The best practice frontier was estimated using one output and five inputs. The output and inputs ${ }^{6}$ were defined based on farmers' cropping practices in rainfed rice production systems. Paddy (unhusked) rice production was the output, measured in kilogram per farm. The defined inputs consisted of (1) manual weeding labor, (2) labor used for other activities and other services, (3) intermediate inputs (seed and chemical inputs) - defined as variable inputs, (4) land, and (5) capital - the latter two reflecting fixed inputs. Fertilizer and herbicide costs were aggregated into intermediate input costs to avoid "zero-observation" as many farmers did not use all of them. Fertilizer costs included expenditures (computed based on farmer declaration) on organic manure and mineral fertilizer. Labor was measured in hours and included family labor as well as hired labor. Labor was computed based on the number of men, women, and children involved and their time spent in each rice farming operation. Time investment was converted into a quality-adjusted measure of labor, using the ratio 0.5 for children, 0.75 for women, and 1 for men (CIRAD-GRET-MAE, 2002, p. 323). Area under rice was measured using a global positioning system (GPS) device (GARMIN, Model GPSMAP 60CSx). To account for the quality of seed, the costs of seeds coming from farmers' harvest were computed using the average price of paddy in each country while the actual (market) prices were used in case seeds were purchased. Herbicides, other inputs and other service costs were measured at their actual prices. Capital costs related to the use of machinery and small materials (hoes, axes, machetes, etc.) were expressed in terms of their annual (linear) depreciation costs (N'cho et al., 2017). Table 1 presents the mean and standard deviation of the output and each input, based on the farmer-specific data of the two surveyed countries. 
Table 1. Mean of farms households and standard deviation of outputs and inputs used in the DEA model

\begin{tabular}{lllll}
\multicolumn{1}{c}{ Variables } & Mean $(\boldsymbol{n = 2 1 5 )}$ Std. Dev. Mean $(\boldsymbol{n}=\mathbf{1 9 1})$ & Std. Dev. \\
Paddy production (kg/farm) & 426 & $(463)$ & 1,756 & $(1,819)$ \\
Land (ha) & 0.24 & $(0.25)$ & 1.53 & $(1.09)$ \\
Capital (FCFA)a & 2,959 & $(3,526)$ & 21,347 & $(37,703)$ \\
Weeding labor (hour) & 195 & $(170)$ & 573 & $(515)$ \\
Other labor (hour) & 333 & $(275)$ & 1,904 & $(1,637)$ \\
Intermediate inputs (FCFA) & 19,735 & $(26,610)$ & 108,576 & $(98,679)$
\end{tabular}

- Note: ${ }^{\text {a }}$ West African CFA franc, the fixed exchange rate is $€ 1=656$ FCFA.

\subsection{Data used in bootstrap regression models}

Studies by Haji (2007), Speelman et al. (2008), Singbo and Oude Lansink (2010), Kokoye et al. (2013), Theriault and Serra (2014), Ayenew et al. (2017), Pede et al. (2018), and Piesse et al. (2018), showed that farmers' technical efficiency is determined by a set of socioeconomic, institutional, and farm-specific factors. Such factors included household size, education, gender, age, years of experience in rice farming, access to agricultural information, land tenure, area under rice, and number of fields. These factors affect farm management and, therefore, are expected to impact technical inefficiency levels (Haji, 2007). To capture the effect of parasitic weed infestation on rice farmers' technical inefficiency, variables such as the parasitic weed infestation level (measured by the proportion of farm area under rice affected by parasitic weeds), manual weeding modalities,,$\underline{7}$ and interaction effects of parasitic weed infestation and manual weeding modalities were introduced in the models. Manual weeding consisted of hand or hoe weeding. Four manual weeding modalities were considered to account for differences in timing and frequency: (1) weeding once early (up to 30 days after sowing (DAS)), (2) weeding once late (>30 DAS), (3) weeding twice, and (4) weeding three times or more. Based on the research by Ekeleme et al. (2009), Toure et al. (2011), and Ogwuike et al. (2014), we expected that weeding once early and/or weeding twice would reduce farmers' technical inefficiency. However, since weeding more than twice significantly reduces the severity of Rhamphicarpa in Benin (N'cho et al., 2014), we expected this to reduce the technical inefficiency even more than weeding once, in case of Rhamphicarpa infestation. The infested area of the rice farm was expected to increase farmers' inefficiency as a larger area infested may require additional work. The complete list of variables used in the truncated bootstrap regression model with their expected signs is presented in Table $\underline{2}$.

Table 2. Expected sign, mean, and standard deviation of variables used in truncated bootstrap regressions

\begin{tabular}{|c|c|c|c|c|c|}
\hline \multirow[b]{2}{*}{ Variables } & \multirow[b]{2}{*}{$\begin{array}{l}\text { Expected } \\
\text { sign }\end{array}$} & \multicolumn{2}{|c|}{ Benin } & \multicolumn{2}{|c|}{ Côte d'Ivoire } \\
\hline & & Mean & $\begin{array}{l}\text { Std. } \\
\text { Dev. }\end{array}$ & Mean & $\begin{array}{l}\text { Std. } \\
\text { Dev. }\end{array}$ \\
\hline $\begin{array}{l}\text { Weeding labor inefficiency (dependent } \\
\text { variable) }\end{array}$ & & 0.69 & 0.35 & 0.58 & 0.35 \\
\hline Gender of farmer ( 1 = female farmer $)$ & \pm & 0.73 & 0.45 & 0.15 & 0.35 \\
\hline
\end{tabular}




\section{Variables}

Education (number of years completed) Household size (number of individuals)

Area under rice (ha)

Area infested (\%)

MW once early

MW once late

MW more than twicea

MW once* area infested (interaction effect)

MW more than twice* area infested (interaction effect)

Access to information $(1=$ access, $0=$ no access)
Benin Côte d'Ivoire

\begin{tabular}{|c|c|c|c|c|}
\hline $\begin{array}{l}\text { Expected } \\
\text { sign }\end{array}$ & Mean & $\begin{array}{l}\text { Std. } \\
\text { Dev. }\end{array}$ & Mean & $\begin{array}{l}\text { Std. } \\
\text { Dev. }\end{array}$ \\
\hline- & 2.21 & 3.33 & 1.16 & 2.48 \\
\hline- & 7.76 & 5.24 & 10.86 & 5.80 \\
\hline- & 0.24 & 0.24 & 1.53 & 1.09 \\
\hline+ & 35.01 & 36.39 & 15.22 & 22.70 \\
\hline- & 0.03 & 0.18 & 0.28 & 0.45 \\
\hline \pm & 0.01 & 0.1 & 0.10 & 0.30 \\
\hline \pm & 0.52 & 0.50 & 0.14 & 0.34 \\
\hline \pm & 1.44 & 9.48 & 3.20 & 10.66 \\
\hline- & 22.36 & 33.59 & 3.28 & 12.71 \\
\hline - & 0.86 & 0.35 & 0.69 & 0.46 \\
\hline
\end{tabular}

- Notes: MW = Manual Weeding. ${ }^{\mathrm{a}} \mathrm{MW}$ twice is used as base for comparison.

\section{Results}

\subsection{Technical and scale inefficiencies}

The average overall input technical inefficiency, labor technical inefficiencies, and the overall scale inefficiencies are presented in Table $\underline{3}$.

Table 3. Technical and scale inefficiencies of specific inputs

Benin

\begin{tabular}{|c|c|c|c|c|c|c|c|c|c|c|}
\hline 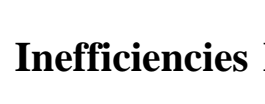 & $\mathbf{N}$ & $\begin{array}{l}\text { Std. } \\
\text { Dev. }\end{array}$ & & & $\begin{array}{c}2.5-97.5 \\
\text { pct. }\end{array}$ & Me & $\begin{array}{l}\text { Std. } \\
\text { Dev. }\end{array}$ & & Max & $\begin{array}{c}2.5-97.5 \\
\text { pet. }\end{array}$ \\
\hline & & 0.35 & 0 & 0 . & $0.63-0.73$ & 0.50 & 0.35 & 0 & 0.9 & .63 \\
\hline 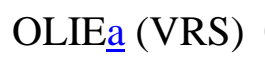 & 0.64 & 0.34 & 0 & 0 & 0.60 & 0.60 & 0.34 & 0 & 97 & .65 \\
\hline NIEa ( & 0.53 & 0.31 & 0 & 0.95 & 57 & 0.41 & 0.28 & 0 & 0.92 & .45 \\
\hline VLIEa (CR & 0.82 & 0.25 & 0 & 0.99 & 35 & 0.71 * & 0.30 & 0 & 0.99 & 0.6 \\
\hline LIEa & 0.84 & 0.25 & 0 & 0.99 & 37 & $0.82 * *$ & 0.29 & 0 & 0.99 & $0.77-$ \\
\hline NIEa (CRS) & 0.68 & .26 & 0 & 0.99 & 1 & 0 . & 0.28 & 0 & 0.97 & 52 \\
\hline SIE & 0.15 & .20 & 0 & 0.92 & $0.12-0.17$ & 0.17 & 0.21 & 0 & 0.90 & $0.14-0.20$ \\
\hline
\end{tabular}

- Notes: pct. $=$ percentile, WLIE $=$ weeding labor technical inefficiency, $\mathrm{CRS}=$ constant returns to scale, OLIE $=$ other labor technical inefficiency, INIE $=$ overall inputs technical inefficiency, VRS = variable returns to scale, OSIE = overall scale

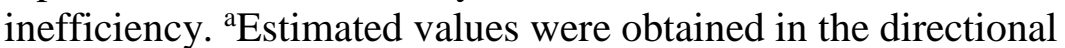
vectors $\left(g_{x_{i}}, g_{y}\right)=\left(x_{w i a b}, 0\right)$ for WLIE, $\left(g_{x_{i}}, g_{y}\right)=\left(x_{o l a b}, 0\right)$ for OLIE, and $\left(g_{x_{i}}, g_{y}\right)=\left(x_{v}, 0\right)$ for INIE, wlab = weeding labor, olab = other labor, $x_{v}=$ variable inputs, $(* *)$ statistically significant at $5 \%$ (2.5th and 97.5 th pct. do not overlap), comparing weeding labor use to other labor use. 
The average overall input technical inefficiency was $41 \%$ and $53 \%$ for the VRS model, and $58 \%$ and $68 \%$ for the CRS models in Côte d'Ivoire and Benin, respectively. The mean technical inefficiency of weeding labor was $58 \%$ and $69 \%$ for VRS, and $71 \%$ and $82 \%$ for CRS in Côte d'Ivoire and Benin, respectively. The mean technical inefficiency of other labor was $60 \%$ and $64 \%$ (for VRS), and $82 \%$ and $84 \%$ (for CRS), in Côte d'Ivoire and Benin, respectively.

In both countries, weeding labor technical inefficiencies were not significantly different from other labor use inefficiencies (OLIE), except in Côte d'Ivoire for the CRS specification where weeding labor technical inefficiency (WLIE) was smaller than OLIE (Table $\underline{3}$ ). $\underline{8}$

The overall scale inefficiency (OSIE) was $17 \%$ in Côte d'Ivoire and $15 \%$ in Benin. In Benin, only $6 \%$ of farmers were scale efficient (OSIE $=0$, i.e., operating at constant return to scale). In Côte d'Ivoire, only $10 \%$ of farmers were scale efficient. Hence, most farmers in the sample in both countries were scale inefficient. Fig. 2 shows the distribution of technical inefficiency scores among the farmers in the sample for overall inputs and weeding labor. The distribution of technical inefficiencies of weeding labor indicated the presence of two rather extreme clusters of farmers in both countries. On the one hand, farmers were clustered at a higher inefficiency level (WLIE $>80 \%$ ), while at the same time there was a cluster of very efficient farmers (WLIE < 20\%). The intermediate cluster $(20 \% \leq$ WLIE $\leq 80 \%)$ was less represented in both countries, indicating a divergence between farmers with respect to their weed management abilities.

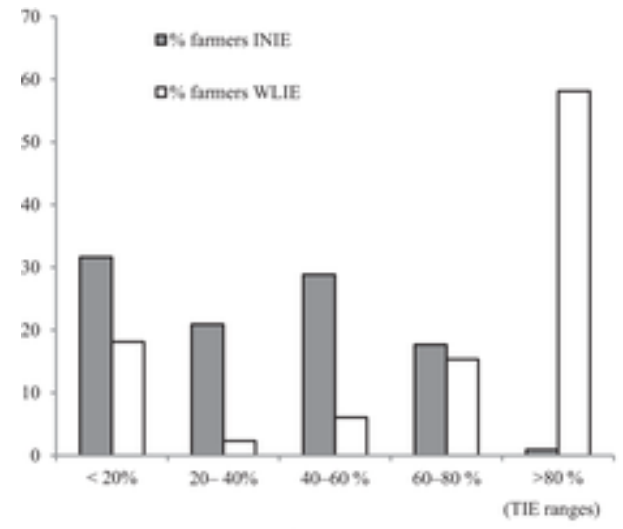

(a)

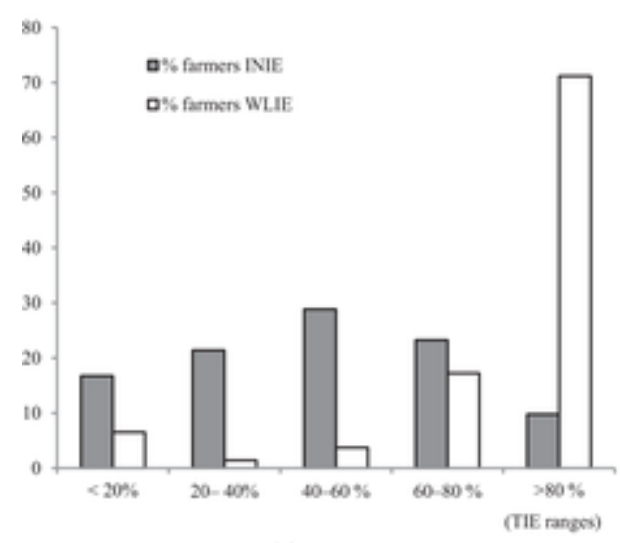

(c)

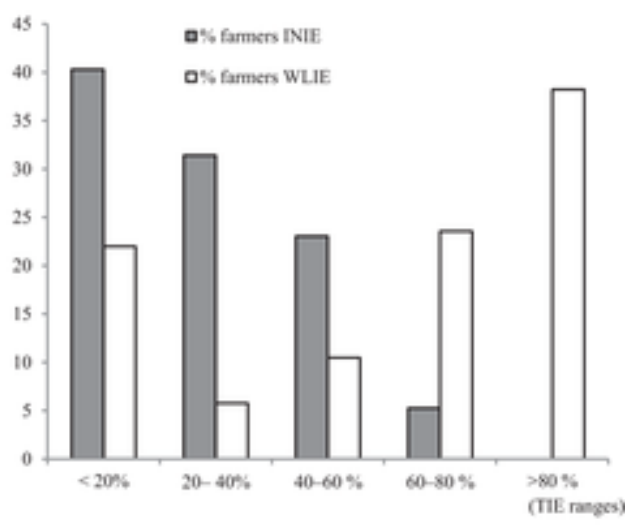

(b)

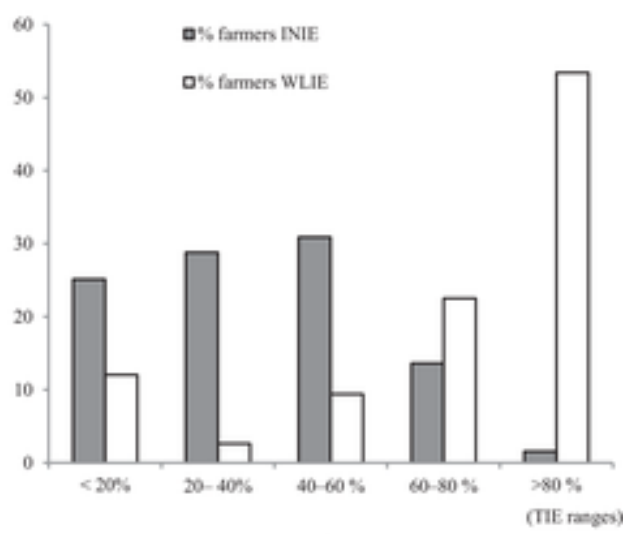

(d)

Figure 2

Open in figure viewerPowerPoint 
Distribution of overall inputs and weeding labor technical inefficiency scores per country.

a. Variable returns to scale (VRS), Benin.

b. Variable returns to scale (VRS), Côte d'Ivoire.

c. Constant returns to scale (CRS), Benin.

d. Constant returns to scale (CRS), Côte d'Ivoire.

Notes $:$ INIE = overall inputs technical inefficiency, WLIE = weeding labor technical inefficiency, $\mathrm{CRS}=$ constant returns to scale, $\mathrm{VRS}=$ variable returns to scale, $\mathrm{TIE}=$ Technical Inefficiency.

Since the focus of this study is on weeding labor inefficiency in the presence of parasitic weeds, we drew the distribution of weeding labor inefficiency for farms infested with parasitic weeds and compared it to that of farms not infested by these weeds (Fig. $\underline{3}$ ). The two distributions appear identical in both countries for the VRS as well as the CRS specification. The distributions for the subsamples of parasitic-infested and noninfested farms both followed cluster shapes similar to what was observed for the whole sample. In order to test whether the distribution of overall input inefficiencies were the same for the parasitic weedinfested farms and the noninfested farms, we ran the adapted Li test.

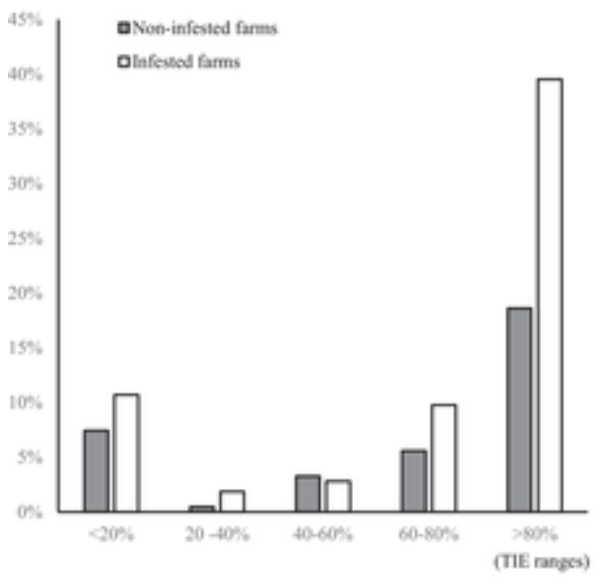

(a)

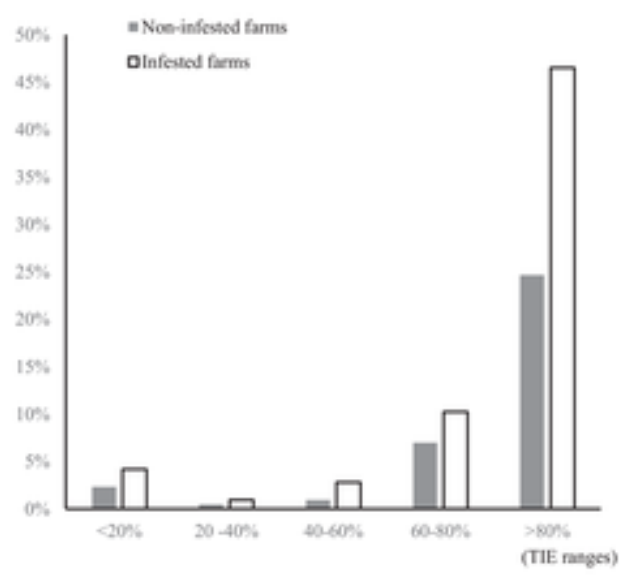

(c)

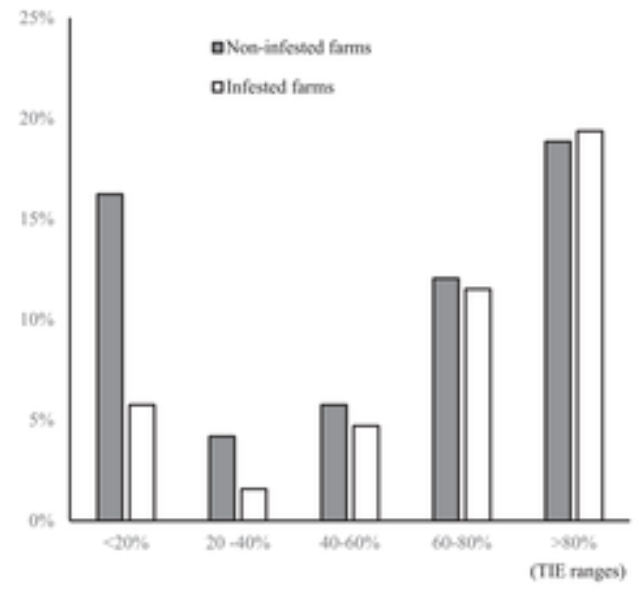

(b)

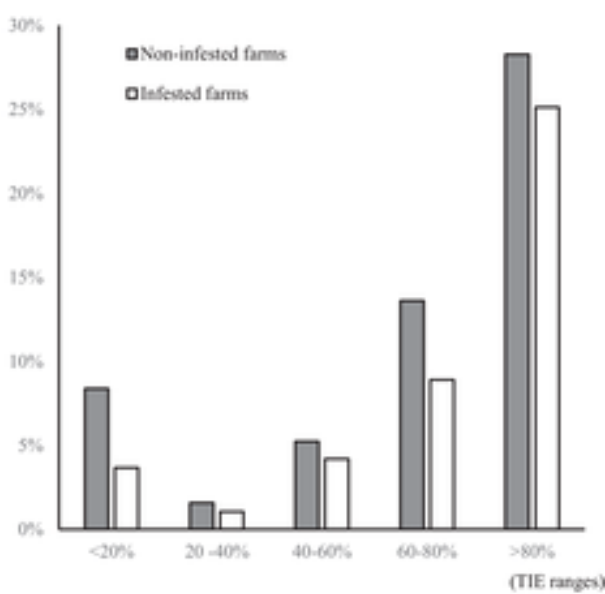

(d) 


\section{Figure 3}

Open in figure viewerPowerPoint

Distribution of weeding labor technical inefficiency scores per farm infestation status per country.

a. Variable returns to scale (VRS), Benin.

b. Variable returns to scale (VRS), Côte d'Ivoire.

c. Constant returns to scale (CRS), Benin.

d. Constant returns to scale (CRS), Côte d'Ivoire.

While for the Benin sample, the test results were not significant $(P>0.1$; not reported) for either overall inefficiency or weeding labor inefficiency, in Côte d'Ivoire both inefficiency distributions were significant for the VRS specification only $(P=0.0097$ for INIE and $P=$ 0.0249 for WLIE). Hence, the null hypothesis of equal distributions for the subsamples of parasitic weed-infested and noninfested farms was not rejected for Benin, while it was rejected for Côte d'Ivoire for the VRS specification. This suggests that the distributions of farmers' overall inefficiency and weeding labor inefficiency were independent of the parasitic weed infestations of farms in Benin, while the opposite was observed in Côte d'Ivoire.

Furthermore, the difference of mean inefficiency scores between the subsamples of infested and noninfested farms was checked using the 2.5th and 97.5th percentiles of their respective mean inefficiency scores (Table 4$)$. Significant differences $(P<0.05)$ were found only for INIE and WLIE for the VRS specification in Côte d'Ivoire (Table 4), indicating that for overall input and weeding labor, the technical inefficiency for noninfested farms is generally lower than that for infested farms.

Table 4. Mean values of specific technical inefficiencies of noninfested and infested farms and their 2.5 th and 97.5 th percentiles

\begin{tabular}{|c|c|c|c|c|c|}
\hline & & & Benin & Côte & e d'Ivoire \\
\hline $\begin{array}{c}\text { Technical } \\
\text { inefficiencies }\end{array}$ & $\begin{array}{c}\text { Infestation status }(1=\text { yes, } 0 \\
=\text { no })\end{array}$ & Mean & $\begin{array}{l}2.5-97.5 \\
\text { pct. }\end{array}$ & Mean & $\begin{array}{l}2.5-97.5 \\
\text { pet. }\end{array}$ \\
\hline INIE (VRS) & 1 & 0.53 & $0.48-0.58$ & $0.48 * *$ & $0.42-0.54$ \\
\hline & 0 & 0.53 & $0.46-0.61$ & $0.36 * *$ & $0.31-0.42$ \\
\hline WLIE (VRS) & 1 & 0.70 & $0.65-0.76$ & $0.66 * *$ & $0.59-0.73$ \\
\hline & 0 & 0.66 & $0.57-0.74$ & $0.52 * *$ & $0.45-0.59$ \\
\hline OLIE (VRS) & 1 & 0.65 & $0.59-0.70$ & 0.66 & $0.59-0.73$ \\
\hline & 0 & 0.63 & $0.55-0.72$ & 0.55 & $0.49-0.62$ \\
\hline INIE (CRS) & 1 & 0.67 & $0.63-0.71$ & 0.59 & $0.53-0.65$ \\
\hline & 0 & 0.70 & $0.64-0.76$ & 0.57 & $0.51-0.63$ \\
\hline WLIE (CRS) & 1 & 0.82 & $0.77-0.86$ & 0.74 & $0.68-0.80$ \\
\hline & 0 & 0.81 & $0.76-0.87$ & 0.68 & $0.62-0.74$ \\
\hline OLIE (CRS) & 1 & 0.84 & $0.80-0.88$ & 0.83 & $0.77-0.89$ \\
\hline
\end{tabular}


Benin

$$
\begin{aligned}
& \text { Infestation status } \\
& =\text { no })
\end{aligned}
$$

$\begin{array}{cccc}\text { Mean } & \begin{array}{c}\mathbf{2 . 5 - 9 7 . 5} \\ \text { pct. }\end{array} & \text { Mean } & \begin{array}{c}\mathbf{2 . 5 - 9 7 . 5} \\ \text { pct. }\end{array} \\ 0.83 & 0.76-0.89 & 0.81 & 0.75-0.86\end{array}$

- Notes: pct. $=$ percentile, INIE $=$ overall inputs technical inefficiency, WLIE $=$ weeding labor technical inefficiency, OLIE = other labor technical inefficiency, CRS $=$ constant returns to scale, $\mathrm{VRS}=$ variable returns to scale, $\left({ }^{* *}\right)$ statistically significant at $5 \%$ (2.5th and 97.5 th pct.).

\subsection{Determinants of inefficiency of weeding labor}

The results of the truncated bootstrap regression showing the sources of weeding labor inefficiency are displayed in Table $\underline{5}$. The scale inefficiency estimates showed that less than $10 \%$ of the farmers in both countries operated at CRS. Moreover, results from the VRS, CRS, and NI-RS estimation (in Benin $\mathrm{D}^{\mathrm{V}}(0.7)<\mathrm{D}^{\mathrm{NI}}(0.9)=\mathrm{D}^{\mathrm{C}}(0.9)$ and in Côte d'Ivoire $\mathrm{D}^{\mathrm{V}}(0.6)<$ $\left.\mathrm{D}^{\mathrm{NI}}(0.7)=\mathrm{D}^{\mathrm{C}}(0.7)\right)$ confirmed that the technologies exhibit IRS in both countries. Hence, only the technical inefficiency estimates of the VRS specification were used for the second stage regression.

Table 5. Results of the truncated bootstrap regression for sources of weeding labor technical inefficiency

Variables

Inefficiency effect variables

Constant

Female farmer

Education

Household size

Area under rice

Area infested

MW once early

MW once late

MW more than twicea

MW once* area

infested

MW more than

twice*area infested
Benin

Coefficients Std.

$0.80 * *$

0.08

0.01

0.003

$-0.32 * *$

0.001

$-0.20$

$-0.36$

$-0.03$

0.001

$-0.0001$

0.10

0.06

0.01

0.005

0.005

0.1

0.001

0.28

0.07

0.005
$[-0.77$,

$0.32]$

$-0.14 * *$

$[-1.1,0.18]-0.07$

0.12

$[-0.17$,

$0.11]$

$[-0.01$,

$0.01]$

0.001

$[-0.003$, 0.003]

\section{Côte d'Ivoire}

Std. $\quad 95 \%$ CI
Err.

$0.08 \quad[0.66,0.97]$

0.07

$[-0.08$,

$0.18]$

$0.01 \quad[-0.04$,
-0.002

$0.004 \quad[-0.01$,

$0.01]$

$[-0.07$,

0.03 ]

[4e-04,

$0.005] \underline{b}$

$0.07 \quad[-0.28$,

$-0.02]$

$[-0.26$,

$0.11]$

$[-0.06$,

$0.10 \quad 0.30]$

$0.003 \quad[-0.004$,

$0.007]$

$0.003 \quad[-0.01$, 


\begin{tabular}{|c|c|c|c|c|c|c|}
\hline Variables & \multicolumn{3}{|c|}{ Benin } & \multicolumn{3}{|c|}{ Côte d'Ivoire } \\
\hline $\begin{array}{c}\text { Inefficiency effect } \\
\text { variables }\end{array}$ & Coefficients & $\begin{array}{l}\text { Std. } \\
\text { Err. }\end{array}$ & $95 \% \mathrm{CI}$ & Coefficients & $\begin{array}{l}\text { Std. } \\
\text { Err. }\end{array}$ & $95 \% \mathrm{CI}$ \\
\hline Access to information & 0.004 & 0.07 & $\begin{array}{l}{[-0.14} \\
0.15]\end{array}$ & -0.07 & 0.05 & $\begin{array}{l}{[-0.17} \\
0.04]\end{array}$ \\
\hline Log likelihood & -56.497823 & & & -31.893233 & & \\
\hline Prob $>$ chi $^{2}$ & 0.00 & & & 0.00 & & \\
\hline
\end{tabular}

- Notes: $\mathrm{MW}=$ manual weeding, $\mathrm{CI}=$ confidence interval. ${ }^{\mathrm{a}} \mathrm{MW}$ twice is the base category. ${ }^{\text {b The }} 90 \%$ CI was reported. $* * P<0.05$ and $* P<0.1$ based on the bootstrap $95 \%$ and $90 \% \mathrm{CI}(L=2,000$ replications $)$.

In Côte d'Ivoire, weeding once (early) decreased technical inefficiency $(P>0.05)$, while the effect of a single late weeding intervention was not significant (Table $\underline{5}$ ). Weeding early once and having a higher education were associated with a lower technical inefficiency. A larger share of plot infested was associated with a higher inefficiency. Ceteris paribus, an increase of $1 \%$ in area infested by parasitic weeds increases the WLIE by $0.3 \%$. An additional year of education decreases the WLIE by $2 \%$. In Benin, only larger farms were associated to a lower inefficiency $(P<0.05)$ while, contrary to Côte d'Ivoire, the technical inefficiency of weeding labor did not increase with an increase in infested area $(P>0.1)$. Weeding more than twice had no significant effect on inefficiency $(P>0.1 \%)$ in either of the two countries.

\section{Discussion}

The results of the directional input distance function show that smallholder, rainfed rice farming systems are overall technically inefficient in their use of inputs. This is consistent with findings by N'cho et al. (2017), indicating that substantial amounts of production resources can be saved, while preserving the current level of output. The technical inefficiency of weeding labor was high. This was expected because manual weeding is highly labor intensive and farmers do not have many effective alternatives (Rodenburg et al., 2019). The high technical inefficiency found in this study is consistent with previous studies that indicate rice production is constrained by inefficient use of inputs in SSA (Mujawamariya et al., 2017). For example, Sherlund et al. (2002) found high technical inefficiency in smallholder rice farm systems in Côte d'Ivoire. Mujawamariya et al. (2017) argued that in SSA, the risk perceived by rice farmers aggravates inefficiency. The high technical inefficiency of weeding labor can be explained by its crucial role in the production. In rainfed rice systems of SSA, a lack of proper weeding results in high production losses (Rodenburg and Johnson, 2009). Farmers rely mainly on manual weeding due to the limited number of effective and affordable weed management practices available to them (Rodenburg et al., 2019). Parasitic weeds are expected to cause a higher damage level to the crop compared to ordinary weeds because, in addition to the ordinary crop-weed competition, they also parasitize host crop plants. Therefore, in order to prevent serious production losses, farmers in parasitic weed-infested fields apply substantially more labor resources for weeding. The majority of that labor is family labor (Singbo and Oude Lansink, 2010), which is not reflected in actual expenditures and farmers may not consider the opportunity costs of this. Similar to the case of herbicide use, as underlined by Olson and Eidman (1992), weeding labor might be used more to manage risks than to maximize profits. Farmers who perceive a high risk of production losses for their farms infested by parasitic weeds may overreact, 
resulting in an excess use of labor for weeding and thereby increase technical inefficiency more significantly than in the case of ordinary weeds. This is particularly true for Côte d'Ivoire where weeding labor inefficiency was higher on infested farms than on noninfested farms (Section 4.1). Since manual weeding is labor-intensive, the completion of this task is often delayed, resulting in lower rice yields despite the large amount of labor (Ogwuike et al., 2014; Rodenburg and Johnson, 2009). To be efficient, timing of weeding interventions in rice is very important as was shown by Johnson et al. (2004). A relatively small time investment (e.g., one or two weeding operations) at critical early crop stages may result in a higher technical efficiency of weeding labor and lower weed-inflicted yield losses compared to a relatively large time investment (e.g., more than two weeding interventions) at later, less critical crop stages (Toure et al., 2011). In the case of parasitic weeds, an early intervention may be even more important as it will reduce the period of parasitism. In the case of Rhamphicarpa fistulosa, a facultative parasitic weed that starts as an ordinary weed and only starts parasitizing its host once it has developed into a seedling, early weeding may even completely avert parasitism (Kabiri et al., 2016).

The large difference observed between CRS and VRS overall technical inefficiency scores suggests the presence of significant scale inefficiencies in the sample. More than $92 \%$ of the farmers did not operate at their optimal scale. The results of the bootstrap regression indicated that technical inefficiencies of weeding labor indeed decreased with larger farms (mainly in Benin). A possible explanation of this observation is that larger farms are realizing IRS. This is supported by Coelli et al. (2002), who showed that if farms were realizing IRS, the area cropped is expected to have a significant positive impact on efficiency levels (decreasing inefficiency). Similar results were obtained by Balezentis et al. (2014) using a DEA bootstrap approach, suggesting that increasing area under rice may raise the technical efficiency. This implies that increasing the scale of farming systems could improve the efficiency of the use of inputs. This is consistent with the first stage estimates that the farming systems are exhibiting IRS. A substantial scale inefficiency was also reported by Singbo and Oude Lansink (2010) in lowland farming systems in Benin. However, the results are not consistent with Haji (2007) who found that scale inefficiency was nearly absent in the more traditional farming systems of smallholder farms in Eastern Ethiopia.

Farmers with parasitic weed-infested rice fields recognize that hand weeding may be effective (in particular against the facultative parasite Rhamphicarpa fistulosa), but also consider these interventions overly laborious (Tippe et al., 2017a). An important implication of the results of the current study is that, with the actual level of technology, farmers can substantially reduce weeding labor and still produce the observed output (conditional on the use of other inputs too). This implies that by improving the technical efficiency of weeding labor, farmers could reallocate a significant fraction of labor to other productive activities of the household without decreasing rice production or increasing the use of other inputs. Improving technical efficiency of weeding labor might require training of farmers in Good Agricultural Practices (GAP) for rainfed rice systems and in labor saving strategies (e.g., optimized weeding timing). Although recent efforts already resulted in defining feasible parasitic weed control strategies for subsistence rice farmers in SSA (e.g., Randrianjafizanaka et al., 2018; Tippe et al., 2017b), more strategies need to be developed and disseminated. While such strategies should preferably be labor saving, other important criteria for increased adoption potential are affordability, accessibility, feasibility in terms of implementation, and control efficacy (Tippe et al., 2017a). 
The large difference in the distributions of technical inefficiency scores of weeding labor and overall inputs indicates that farmers performed differently in managing their overall production process compared to managing weeds. The fact that a large fraction of the farmers in both countries exhibit a high level of inefficiency suggests that the majority of farmers did not perform well with regards to weed management. This finding suggests the need for actions that focus on solving the general weed management problem in rainfed rice systems in SSA. The majority of subsistence rice farmers has limited resources and limited weed management capacities. The farmers operating fully efficiently may have different profiles with respect to weed management compared to the farmers that are operating less efficiently. For example, they may be exposed to agricultural training and learn possible labor-saving strategies such as optimal timing of weeding. Education was linked to decreased technical inefficiencies, and this is in line with empirical findings in SSA. For instance, a study by Ayenew et al. (2017) showed that literate smallholder farmers are more likely to be technically efficient in agriculture than their illiterate counterparts. Sherlund et al. (2002) showed that education is positively and significantly correlated with technical efficiency for smallholder rice farmers in Côte d'Ivoire. Furthermore, college level or higher education was associated to higher technical efficiency than secondary and elementary education. Likewise, Schut et al. (2015) identified agricultural education and awareness raising among farmers and extension agents as one of the most important drivers for innovation to better address parasitic weed problems in rice. Finally, for extension services to be more effective in training farmers on new technologies, the quality and mode of service delivery should also improve. Achandi et al. (2018) showed that extension services for rice production systems in SSA are not yet gender inclusive enough to reach all farmers effectively.

The results of the second stage truncated bootstrap regression suggest that farmers can reduce the technical inefficiency of weeding labor by increasing their area under rice (mainly in Benin) or by adjusting their weeding operation to one early manual weeding (in Côte d'Ivoire). In Côte d'Ivoire, weeding once but early had a significant negative effect on technical inefficiency of weeding labor while weeding once but late did not. These results again confirm the importance of the development of adapted weeding regimes ${ }^{9}$ with proper timing of interventions (see Ekeleme et al., 2009; Johnson et al., 2004; Toure et al., 2011). The insignificant coefficient of weeding more than twice indicates that, in both countries, it has similar effects on technical inefficiency of weeding labor as weeding thrice or more (weeding twice is the base category). This means that at the current technology level, keeping all other inputs constant, there might not be a need to weed more than twice to produce the current output level. Ogwuike et al. (2014) concluded that weeding an upland rice crop more than once increases the weeding labor efficiency (by about 37\%) and rice productivity (by more than 27\%); hence, the optimum number of weeding operations is most likely two. In Côte d'Ivoire, the effect (interaction effect) of one manual weeding on weeding labor inefficiency of a field infested by parasitic weeds was positive while the effect of weeding a parasitic weed-infested field more than twice was negative. This means that, when rice farms become infested by parasitic weeds, the effect of weeding once on technical inefficiency changes from negative to positive, while the opposite effect is observed with weeding more than twice. However, these joint effects were not significant. In Benin, both corresponding effects remain negative and nonsignificant regardless of the infestation status of the fields. These nonsignificant effects indicate that both weeding once and weeding more than twice might not be effective when plots become infested by parasitic weeds. The negative and nonsignificant joint effects of weeding more than twice and infestation by parasitic weeds indicate that, in the presence of parasitic weeds, farmers tend to weed more than twice in their attempt to secure their harvest. This suggests that future research on parasitic weed 
management strategies needs to investigate both the appropriate weeding timings and the number of weeding interventions, as well as alternative cost-effective strategies to hand weeding. Since the research solely used the efficiency analysis approach to account for economic benefits of alternative parasitic weed management methods in rice farming, future research should use bioeconomic simulation models which combine biological and economical outcomes to provide better insights in the composition of strategies that provide the most accurate and most cost-effective control.

\section{Conclusion}

This article analyzes the technical inefficiency of weeding labor and other inputs in rainfed rice systems in the presence of parasitic weeds in Côte d'Ivoire and Benin. In the first stage, a directional input distance function with DEA approach was used to estimate the inefficiency scores pertaining to a specific input. In the second stage, a robust truncated bootstrap regression was used to identify sources of technical inefficiency of weeding labor.

We found that substantial inefficiency exists in both countries for overall input, weeding labor, and other labor, suggesting that at the current technology level farmers can maintain their production level and still save inputs. In addition, substantial overall scale inefficiencies were found in both countries, suggesting that an increase in the scale of production systems will reduce the technical inefficiency. Results from the truncated bootstrap regression further suggest that the currently used manual weeding regimes and number of weeding interventions on farms infested by parasitic weeds are not efficient in controlling the parasitic weeds. Operating fully efficiently would save a substantial amount of labor that can be allocated to other productive activities of the household without decreasing the current rice production levels.

To the best of our knowledge, this study is the first to explicitly raise the crucial issue of weeding labor inefficiency in smallholder rainfed rice farming systems of SSA. Overall, the study contributes to the broader literature on production efficiency of rice systems by showing that in smallholder rainfed rice farming systems of SSA, coping with parasitic weed infestations, there is scope for improving the technical efficiency of weeding labor.

These findings have significant policy implications since the extent of estimated technical inefficiency prevailing in an agricultural economy matters when determining whether scarce agricultural development funds are best spent to develop improved technologies or to train farmers on how to better use existing improved technologies. We therefore recommend that National Agricultural Research and Extension Systems (NARES), in collaboration with international organizations in agricultural research, develop research and extension programs aiming at reducing technical inefficiency of weeding labor. The current study suggests this can be achieved by increasing the scale of production, using effective alternative weeding modalities, enhancing agricultural education of farmers, raising awareness on the parasitic weeds among farmers and agricultural extension agents, and exploring labor-saving and costeffective parasitic weeding technologies. This could enhance rainfed rice systems productivity and contribute to improving food security in countries affected by parasitic weed problems.

Although the second stage truncated bootstrap estimation of the study aimed at identifying factors significantly affecting the inefficiency of weeding labor, covariates available in the 
data set were restricted to farm and farm household characteristics. Future research may explore and develop models that combine biological, ecological, and economical outcomes to enhance our understanding of what the most cost-effective and accurate management strategies are for parasitic weed-infested rice farms. Moreover, since the study only focused on the technical relationship between inputs and outputs, future studies could include the cost of input and investigate the economic efficiency of weeding labor.

\section{Acknowledgments}

The authors appreciate the valuable support and collaboration of Louise Akanvou from the National Agricultural Research Centre of Côte d'Ivoire (CNRA), as well as the field technicians and farmers from Benin and Côte d'Ivoire. We acknowledge the financial support of the Netherlands Organization for Scientific Research - Science for Global Development (NWO-WOTRO; project: PARASITE; grant number: W 01.65.327.00) and the CGIAR Research Program on Climate Change, Agriculture and Food Security (CCAFS).

- 1 The overall input scale inefficiencies were computed following Färe et al. (1985).

- 2 Since the CRS and VRS specification alone are not able to determine whether the technology exhibits decreasing or increasing returns to scale, an additional computation of either the nondecreasing (ND)-primal or the nonincreasing (NI)primal is required (Fukuyama, 2003).

- 3 In the estimation of each directional input distance function model, only the target input changes. Thus, for overall input inefficiency (INIE), all variable inputs $\left(x_{v}\right)$ varied, including weeding labor, while fixed inputs remained unchanged. For Weeding Labor Inefficiency (WLIE), only weeding labor (wlab) altered and all other inputs remained constant. For Other Labor Inefficiency (OLIE), only Other Labor (olab) was considered variable, while all other remaining inputs were kept constant.

- 4 In defining the subvector inefficiency, only the target input changes while other inputs and the output remain unchanged.

- 5 Details on the algorithm used in Stata for the bootstrap are available upon request from the authors.

- 6 An outlier test was performed in FEAR, and outliers (only 6) were removed from the analysis

- 7 Weeding modalities are defined by 1 the number of days between sowing and each weeding operation and $\underline{2}$ the number of weeding operations required.

- 8 Weeding labor inefficiency was compared to other labor and overall inefficiency using the range of 2.5 th-97.5th percentiles. The compared mean values are different if the range of 2.5th-97.5th percentile did not overlap, otherwise the difference was not significant.

- 9 This refers to the number of DAS at which each weeding operation is conducted. 